\title{
THE PURPOSE OF THE PRESENT INVESTIGATION
}

On the basis of the preceding review of literature it may be concluded that there are several aspects in the ontogenesis of the gastric epithelial cells which have not been sufficiently clarified. The purpose of the present investigation is therefore to seek answers to the following problems:

I At what stage of embryonic development do the four human gastric epithelial cell types morphologically examined undergo differentiation?

II At what stage of embryonic development does the parietal cell show the enzymatic activity characteristic of it in the adult?

At what stage are the first signs of productive protein synthesis and enzyme production seen in the chief cells?

When and in what form are intestinal type cells observed in different parts of the foetal stomach? V At what stages of development do the pyloric and cardiac glands appear? 